\title{
Response of the Leek (Allium porrum)-Mycorrhizal Fungus Symbiosis to Cutting Levels, Light Exposure and Seedling Density
}

\author{
G. Nowo Nekou, A.-M. Sontsa-Donhoung, Hawaou, M. Bahdjolbe, R. Tobolbaï, and D. Nwaga
}

\section{ABSTRACT}

This work aims to assess the leek-arbuscular fungus symbiosis response to the effect of cutting and light exposure on the one hand, and the impact of seedling density on this symbiosis on the other hand. Allium Porrum was grown in a container in two different trials. Four species of arbuscular mycorrhizal fungi, Glomus hoi, Scutellospora gregaria, Rhizophagus intraradices and Gigaspora margarita were used to constitute the mycorrhizal inoculum. After 150 days of growth and inoculation, a series of cuts were made on the aerial part $(0 \%=$ zero cut, $50 \%=$ half cut, $100 \%$ $=$ whole cut $)$. Plants that had undergone these treatments were placed in shade and sun for 30 days. The leek density per bag was varied by the order of $1,2,3$ and 4 plant (s) by the pocket density test. Results showed that for $0 \%$ of cut in the shade, the vesicle occurrence decreases from $83.33 \%$ to $52.22 \%$, and from $90 \%$ to $25.5 \%$ for $50 \%$ of cut in the shade. On the other hand, there is a significant increase in intra-root spores for a complete cut compared to other levels of cuts. For extra-root sporulation, under light, cuts have a negative and weak effect (from -11 to -3\%) while in the absence of light, cuts have significant positive effects (from +16 to $+61 \%$ ). Regarding seedling density, the best root colonization $(90 \%)$ and biomass production (14 $\mathrm{g}$ ) are obtained with three plants per pot, but it is rather with a density of two plants per pot that extra-root sporulation is higher (153 spores/g). Variation in light, cut level and density significantly affects the development of mycorrhizal fungi.

Keywords: leek, mycorrhizae, cut, light, density.

\section{INTRODUCTION}

A mycorrhiza represents a symbiotic association between telluric fungi and the roots of plants. This association concerns nearly $80 \%$ of land plants [1]. Mycorrhizal symbiosis is known for its ability to provide plants with better access to soil nutrients, helping them to better resist environmental stresses (drought, salinity, pathogen attacks) [2]. Tropical soils, for example, are highly degraded and their mycorrhizal potential remains low [3], despite the mycorrhizal diversity they harbor [4]. In Cameroon, the
Published Online: May 11, 2021

ISSN: $2684-5199$

DOI:10.24018/ejbio.2021.2.3.184

\section{G. Nowo Nekou}

Department of Microbiology,

University of Yaounde 1, Yaounde,

Cameroon.

(e-mail: nekouguillain@gmail.com)

A.-M. Sontsa-Donhoung

Department of Microbiology,

University of Yaounde 1, Yaounde,

Cameroon.

Department of Economic and Environmental Studies, National Education Center, Ministry of Scientific Research and Innovation, Cameroon.

(e-mail: martialdonhoung ${ }^{\circledR}$ yahoo.fr)

Hawaou

Department of Microbiology, University of Yaounde 1, Yaounde, Cameroon.

(e-mail: dalyhawaou6@gmail.com) M. Bahdjolbe

Department of Microbiology, University of Yaounde 1, Yaounde, Cameroon.

(e-mail: mbahdjolbe@gmail.com)

R. Tobolbaï

Department of Microbiology, University of Yaounde 1, Yaounde, Cameroon.

(e-mail: Richard_tobolbai@yahoo.fr)

D. Nwaga*

Department of Microbiology, University of Yaounde 1, Yaounde, Cameroon.

(e-mail: dnwaga ${ }^{\circledR}$ yahoo.fr)

*Corresponding Author selected arbuscular fungi increased field production in more than 12 crops, in the order of 48 to $478 \%$, [5]. Nevertheless, natural infection of crop plants with AMFs is random and depends on various environmental factors. Inoculation of selected mycorrhizal fungi is currently practiced in the context of sustainable agriculture. [3] reports that a minimum of 50 to 1000 spores / plants is required for more efficiency of this symbiosis. In this sense, several techniques for mass production of mycorrhizal inoculum have been developed, among which are aeroponic culture and the nutrient film technique. It is obvious that these approaches to producing 
AMF by way of soilless crops require a significant technological investment and a high cost [6]. Therefore, simple and inexpensive soil cultivation methods deserve to be encouraged in developing countries.

However, the success of a production technique could depend on mastering the factors that influence AMFs development. The intra-root hyphae, vesicles, intra and extraroot spores are structures capable of ensuring the propagation of AMFs [2]. In addition to being a propagule, the vesicles are a reserve organ, their production is linked to the stage of AMF development and their presence may vary with the allocation of carbon by the host plant [7]; [8]. Analyzes performed on annual plants have shown that spore production increases with plant maturity and at the end of the growing season. Factors such as low light intensity and defoliation, factors limiting photosynthesis and therefore the carbon content in the plant, considerably reduced sporulation as well as colonization of new roots [2]. The literature does not provide information on the factors that influence intra-root spore production and there is not enough evidence to distinguish them from extra-root spores [9].

Thus, it may be appropriate to investigate the impact of factors such as, cuts applied to the above-ground biomass of the plant partner, its exposure to light, and its density on mycorrhizal symbiosis. In addition to the prerequisites for well-known AMFs production, which are obtaining a pure strain, the optimization of growth parameters, must be added the choice of an ideal host plant. Commonly used host plants for the pot culture of mycorrhizal fungi are: Sorghum halepense, Paspalum notatum, Panicum maximum, Cenchrus ciliaris, Zea mays, Trifolium subterraneum, Allium cepa, Chloris gayana [10]; [11]. Allium porrum, for its part, is a model plant for intra-root structures description of AMFs. It has a high mycorrhizal dependence [12], a dense but sparsely branched root system, and is widely reported for the effect of AMFs on its growth, resilience to abiotic conditions, and nutrient content [13]. It is not commonly used for AMF production probably because of its very long cycle spanning two years. However, physiological stress effect and the prolonged observation of the common leek in symbiosis remain to be explored.

\section{MATERIAL AND METHODS}

\section{A. Study Site}

The experiment was carried out at the Botanical Garden of the University of Yaounde I, in the Centre Region (Cameroon). The climate is of the Guinean type characterized by bimodal rainfall, with two rainy seasons and two dry seasons. The annual average temperature is around $27^{\circ} \mathrm{C}$.

\section{B. Preparation of the Substrate}

The substrate used is a forest litter soil collected in EmanaBilik, Yaounde, Cameroon. This soil was mixed with coarse sand at a ratio of 3:1 v/v [14]. The mixture was sterilized in the autoclave for 1 hour at $121^{\circ} \mathrm{C}$ and distributed into $3 \mathrm{~L}$ and $4 \mathrm{~L}$ plastic bags after cooling.

\section{Plant and Fungal Material}

The seeds of the common leek (Allium porrum), elephant boot variety, were obtained from SEMAGRI (Semences
Agricoles). The selected arbuscular fungi specimens used come from Soil Microbiology Laboratory collection, Biotechnology Center of the University of Yaoundé I. The mycorrhizal inoculum consists of four AMF species: Glomus hoi, Scutellospora gregaria, Rhizophagus intraradices and Gigaspora margarita. Inoculation consisted of introducing $30 \mathrm{~g}$ of inoculum inside the $5 \mathrm{~cm}$ deep pockets, followed by sowing the leek seeds.

\section{Experimental Designs}

A first experimental set-up was carried out, nonrandomized and made up of six treatments (cutting levels: 0 $\%=$ zero cutting in shade and in light; $50 \%=$ cut in half in shade and in light; $100 \%=$ entire cut in shade and light). The cuts were made at 150 days of growth after sowing. Light and dark exposures were followed for 30 days. Each treatment was applied to 6 pots having two plants each (a total of 12 plants). A second device was produced, consisting of four treatments (variation in the density of leek plants: 1, 2, 3 and 4 plants per bag of $4 \mathrm{~L}$ ) with 12 pots for each treatment.

\section{E. Data Collection}

Root colonization was evaluated at 180 days for the first device (effect of cuts and light) and 150 days for the second device (seedling density), after transplanting using the method of [15]. The plants were harvested on the above dates and dried at $75^{\circ} \mathrm{C}$ (for 72 hours for biomass assessment). The sporulation at the end of culture was evaluated according to the method of [16].

\section{F. Statistical Analysis}

The data collected was entered into SPSS 16.0 software for analysis of variances (ANOVA), calculation of the least significant difference (PPDS) and to determine the correlations between the studied parameters. The NewmanKeuls test made it possible to carry out a comparative analysis of the means in pairs at the $5 \%$ level. The results, presented in the form of histograms and curves, are produced using Microsoft Excel 2016 software.

\section{RESULTS}

Chemical properties of soils, seedling densities and effect of cuts, exposure to shadow and light are presented in this section.

\section{A. Chemical Properties of Soils}

Table I reports chemical properties of soil. The soil has a neutral $\mathrm{pH}$ (7.1), with a moderate nutrient content $(\mathrm{P}=$ $10.30 \mathrm{mg} / \mathrm{kg}, \mathrm{N}=0.97 \mathrm{~g} / \mathrm{kg}$ and $\mathrm{K}=0.25 \mathrm{cmol} / \mathrm{kg}$ ), high percentage in organic matter $(0.71 \%)$.

\begin{tabular}{cc} 
TABLE I: CHEMICAL PROPERTIES OF SOIL \\
\hline $\mathrm{pH}$ & 7.1 \\
OM $(\%)$ & 0.71 \\
$\mathrm{OC}(\%)$ & 0.41 \\
$\mathrm{~N}(\mathrm{~g} / \mathrm{kg})$ & 0.97 \\
$\mathrm{P}(\mathrm{cmg} / \mathrm{kg})$ & 10.30 \\
$\mathrm{CEC}(\mathrm{cmol} / \mathrm{kg})$ & 14.00 \\
$\mathrm{Ca}(\mathrm{cmol} / \mathrm{kg})$ & 5.08 \\
$\mathrm{Mg}(\mathrm{cmol} / \mathrm{kg})$ & 1.20 \\
$\mathrm{~K}(\mathrm{cmol} / \mathrm{kg})$ & 0.25 \\
$\mathrm{Na}(\mathrm{cmol} / \mathrm{kg})$ & 0.23 \\
\hline
\end{tabular}




\section{B. Effects of Cuts, Exposure to Shadow and Light}

The results of the root thinning and extra-root spores production are presented in this section.

\section{Root Thinning}

Roots staining made it possible to highlight some structures characteristic of the endomycorrhizal symbiosis, in particular the vesicles (1), the intra-root spores (2) and the hyphae (3), (Fig. 1). We observe a variation in the type of intra-root spores in the cut plants.
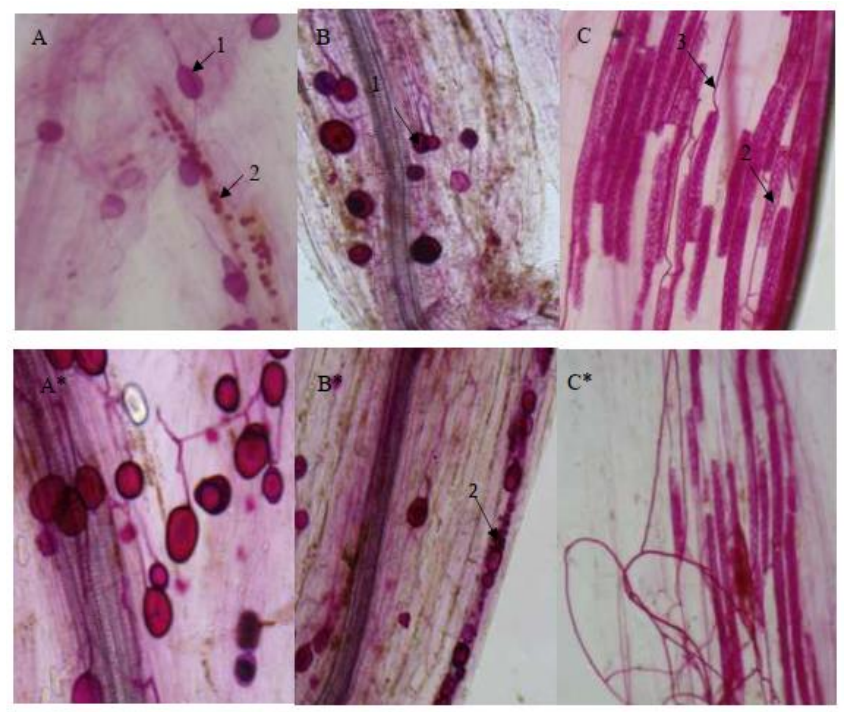

Fig. 1. Leek roots colonized by CMA, staining with acid fuchsin and observed at magnification X100. A and $\mathrm{A}^{*}: 0 \%$ of cutting; $\mathrm{B}$ and $\mathrm{B} *: 50 \%$ of cutting; $\mathrm{C}$ and $\mathrm{C}^{*}$ : $100 \%$ of cutting. Treatments with $\left(^{*}\right)$ were placed in shade. 1: Vesicles; 2: Intra-root spores; 3: Hyphae.

\section{Root colonization}

Fig. 2 shows the variation in root colonization for each mycorrhizal structure (spores, hyphae and vesicles) as a function of cut levels, the effect of darkness and light. It should be noted that cut levels, darkness and light showed no effect on intra-root hyphae ( $100 \%$ for all cut levels, exposure to light and dark). For vesicles, their percentages decreased with increasing cutting and shade exposure levels $(90 \%$ at 0 cutting level and $25.5 \%$ for $50 \%$ cutting: for the same zero cutting level, $83.33 \%$ in the light and $52.22 \%$ in the dark). On the contrary, intra-root sporulation increases with cutting levels $(17.77 \%$ for $0 \%$ cut, $34.44 \%$ for $50 \%$ cut and $77.77 \%$ for $100 \%$ cut).

\section{Production of extra-root spores}

Extra-root sporulation varies with levels of cutting, shade and light exposure (Fig. 3). By the way, under light, sporulation decreases with increasing cut levels (379.39\% at $0 \%$ cut, $367.27 \%$ at $50 \%$ cut and $337.09 \%$ at $100 \%$ cut). Conversely, the level of cut leads to an increase in sporulation in the absence of light $(213.10 \%$ at $0 \%$ cut, $246.93 \%$ at 50 $\%$ cut and $343.26 \%$ at $100 \%$ cut). The highest sporulation $(379.39 \%)$ was recorded in the presence of light at $0 \%$ cut, while the lowest $(213.10 \%)$ was recorded in the dark at $0 \%$ cut.

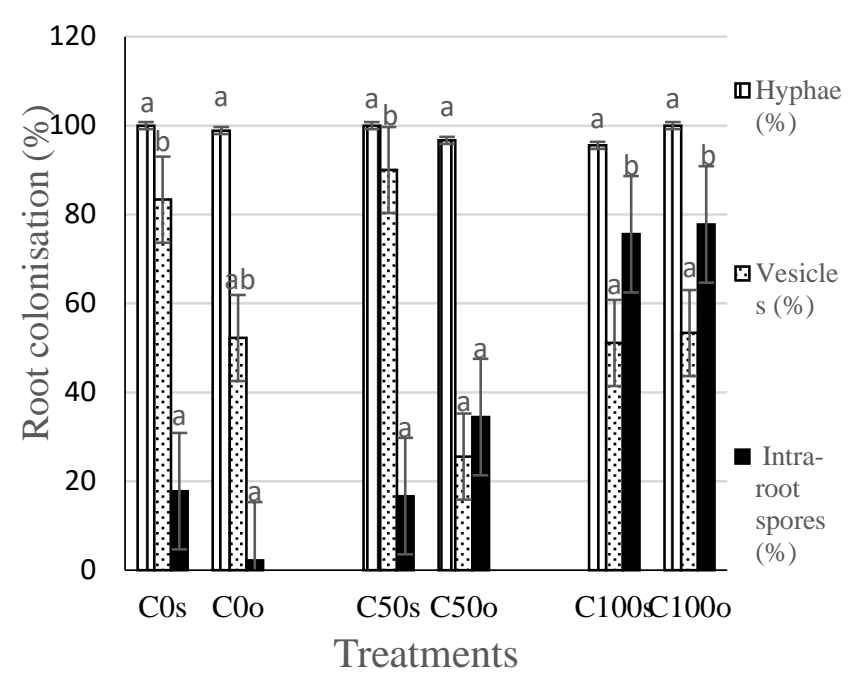

Fig. 2. Effect of cuts and light on root colonization of AMFs 30 days after cutting in common leeks. C0s: zero cut and exposed to light; $\mathrm{C} 0 \mathrm{o}$ : Zero cut and placed in shade; C50s: 50\% cut and exposed to light; C50o: $50 \%$ cut and placed in shade; C100s: full cut and exposed to light; $\mathrm{C} 100 \mathrm{o}$ : whole cut and placed in the shade. Bars with the same letter are not significantly different, at the specified probability threshold $(\mathrm{P}=0.05)$.

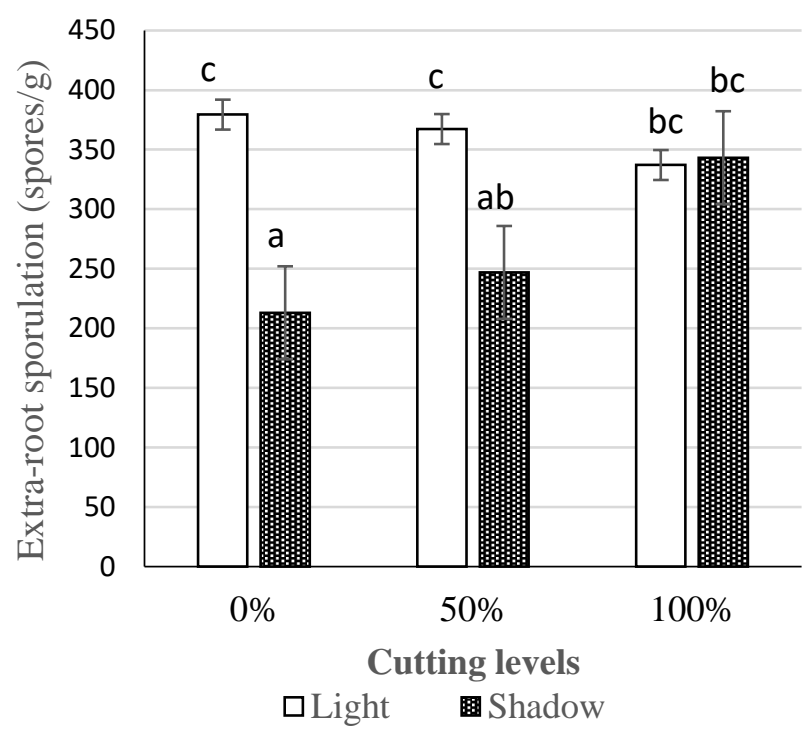

Fig. 3. Effect of sections and light on extra-root sporulation of AMFs in common leeks 180 days after transplanting. $0 \%$ : no cut; $50 \%$ : half cut; $100 \%$ : completely cut.

Bars with the same letter are not significantly different, at the indicated probability threshold $(\mathrm{P}=0.05)$.

\section{Seedling Densities}

The results of the root colonization, extra-root spores' production and biomass production are presented in this section.

\section{Root colonization}

Density effect on root colonization is shown in Fig. 4. It reveals that the percentage of intra-root spores varies significantly $(\mathrm{P}=0.05)$ with density. The highest sporulation was observed with three plants per pot $(31.11 \%)$ while the lowest was recorded with only one plant per pot $(1.11 \%)$. Colonization percentages in vesicles and hyphae are similar for the densities of 1,2 and 3 leeks per pot $(87.77 \%, 92.22 \%$, $91.11 \%$ respectively for the hyphae and $87.77 \%, 90 \%, 90 \%$ 
respectively for the vesicles). The values of these two parameters drop significantly $(\mathrm{P}=0.05)$ for a density of 4 plants per pot (hyphae: $78.88 \%$ and vesicles: $56.66 \%$ ).

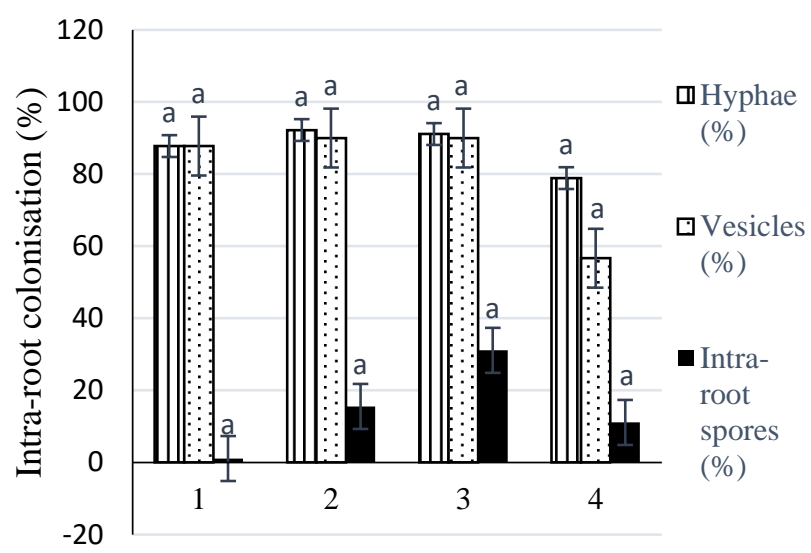

Fig. 4. Effect of seedling density on root colonization of AMFs in common leeks 150 days after transplanting. $1=$ density at one leek plant per pot; $2=$ density of two leek plants per pot; $3=$ density at three leek plants per pot; $4=$ density of four leek plants per pot. Bars with the same letter are not significantly different, at the indicated probability threshold $(\mathrm{P}=0.05)$.

\section{Production of extra-root spores}

Fig. 5 shows the effect of density on extra-root spore production. It shows that it is with a density of 2 feet per pot that the highest sporulation is observed $(152.82 \%)$. In contrast, sporulation recorded at 1 foot per pocket is the lowest $(128.57 \%)$. The values recorded with the densities of 3 and 4 feet per pot, are similar and are intermediate $(133.64 \%$ and $132.93 \%$ respectively $)(P)=0.05 \%)$.

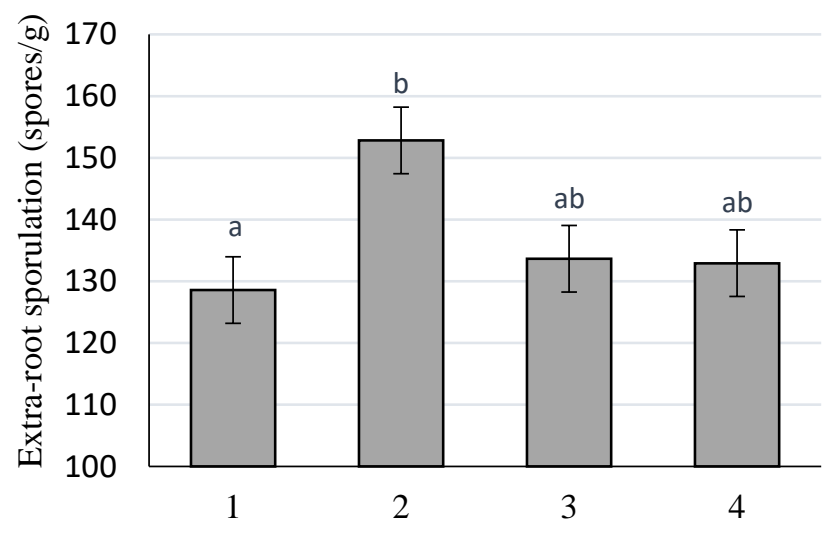

Fig. 5. Effect of seedling density of common leek on extra-root sporulation of AMF 150 days after transplanting. $1=$ density at one leek plant per pot; $2=$ density at two leek plants per pot; $3=$ density at three leek plants per pot; $4=$ density at four leek plants per pot. Bars with the same letter are not significantly different, at the indicated probability threshold $(\mathrm{P}=0.05)$.

\section{Biomass production}

The sowing density significantly influences biomass production in the common leek (Fig. 6). A density of 3 feet per pocket shows a better effect on biomass production $(14.32 \mathrm{~g})$ as opposed to 1 foot per pocket $(8.57 \mathrm{~g})$ which is lower.

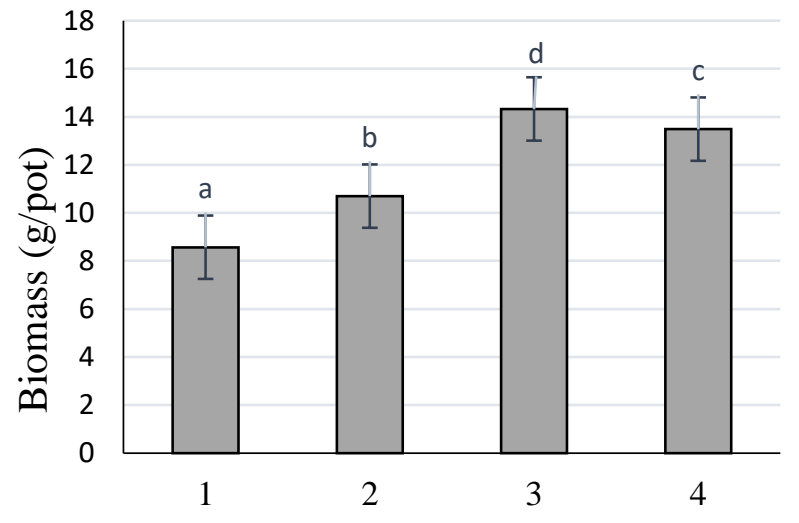

Fig. 6. Effect of sowing density on biomass of common leek 150 days after transplanting. $1=$ density at one leek plant per pot; $2=$ density at two leek plants per pot; $3=$ density at three leek plants per pot; $4=$ density at four leek plants per pot. Bars with the same letter are not significantly different, at the indicated probability threshold $(\mathrm{P}=0.05)$.

\section{DISCUSSION}

Cuts and exposure to darkness decrease the colonization of leek roots, especially in vesicles; the vesicles being the places of nutrient storage for the fungi involved in mycorrhizal symbiosis. By the way, cutting and shade reduces the photosynthetic activity of the host plant. This leads to a drop in the supply of carbohydrates to other parts of the plant, especially the roots [17]. Our observations are different from those of [18] who showed that low light intensity does not significantly affect root colonization and the presence of vesicles. Daft and [19], reported that defoliation inhibits the development of mycorrhizae. Vesicle's abundance is therefore linked to the amount of photo-assimilas given to the fungus. Adequate lighting promotes the production of extraroot spores by AMFs. These observations corroborate those of [18].

In addition, the cuts stimulate the production of intra and extra-root spores. This can be explained by root reserves allocation to AMF and plant physiological response; the roots have an excess of carbon reserves until the plant reestablishes [17]. The variation in intra-root spores' type with the increase in the cutting level may reflect a high development of the least efficient AMF of the consortium because, according to [20], the more efficient species are more demanding in photoassimilas. On the other hand, other authors show that the predominance or development of AMFs vary with the host plant [21]; [22]. Similar to defoliation or attack by herbivorous insects, cutting alters the distribution of carbohydrates within the plant [23]. This imbalance in carbohydrates modifies AMF communities' structure in symbiosis [23], by varying the benefits of mycorrhizae in symbiosis [24]. The variation in these communities can be explained by the fact that the AMFs do not have the same needs in carbohydrates and adopt different strategies for their development [25], in our experiment the increase in the level of sporulation and the variation in Intra-root spores type therefore reflects the predominance and preference of AMF from the consortium for these conditions. Reference [26] observed that herbivorous insects stimulate the development of the symbiosis and also act on mycorrhizal fungi communities' structure. Our data are contrary to those of [27] 
who showed that the cutting levels negatively influence root colonization and extra-root sporulation in the sun (they respectively decrease from $38 \%$ to $26 \%$; from 39 to 15 spores/g).

Regarding seedling density, observations have shown that root colonization and sporulation are inhibited at the density of four plants per pot, as long as they are significantly increased at the density of two plants per pot. In comparison, when legumes (Amorpha fruticosa and Indigofera atropurpurea) are in low density, AMFs develop [22]. These results are different from those of [27] who observed an increase in extra-root sporulation up to the treatment of three plant pot plants. Plant density reflects the level of competition for nutrients and space in a single volume of substrate. In fact, intra-specific competition is accentuated in plants with strong mycorrhizal dependence and on the contrary reduced for plants with negative mycorrhizal dependence [28]. Increasing biomass with plant density should increase the carbonaceous nutrients available to mycorrhizae. But this result can be explained by the need for a balance between the number of plants, the volume of substrate and the development of AMFs; this balance was better when treated with two plants per pot.

\section{CONCLUSION}

This work is an evaluation of the response of the leekmycorrhizal symbiosis to the effect of cuts, light exposure and seedling density. It should be noted that the cuts do not influence the root colonization in hyphae, but decrease the percentage of vesicles and increase the intra-root sporulation. In the presence of light, extra-root sporulation decreases with increasing cutting levels, but the reverse occurs in the dark. Light and cut level impact the relative production of propagules by the AMF species of the consortium used. A density of three feet of common leek per pocket is appropriate for better root colonization by AMFs and biomass production. But for better AMF spore production, a density of two feet per pocket works best. This suggests that the procedure for producing mycorrhizal propagules in pots should be adapted according to the type of AMF. The most efficient, which primarily use photo-assimilas develop better when the plant is not stressed during production. On the other hand, cutting the entire aerial part of the plant at the end of production favors the production of propagules by less efficient AMFs. In addition, the presence of several types of intra-root structures suggests that the type of intra-root spore may be a reliable criterion for identifying AMFs.

\section{CONFLICT OF INTEREST}

The authors declare no conflict of interest whatsoever.

\section{ACKNOWLEDGMENT}

The authors are grateful those who assisted in this study in one way or the other.

\section{REFERENCES}

[1] B. Wang, and Y. Qiu, "Phylogenetic distribution and evolution of mycorrhizas in land plants," Mycorrhiza, vol. 16, pp. 299-363, May 2006. https://doi.org/10.1007/s00572-005-0033-6.

[2] S.E. Smith, and D.J. Read, Mycorrhizal symbiosis, Third edition, Academic Press, Great Britain, 2008, pp. 11-145. https://doi.org/10.1016/B978-012370526-6.50007-6.

[3] D. Nwaga, W.L. Nana, M.E.L. Ngonkeu, N.A. Onguene, N.S Tchameni, A. Maimouna, M.E.C. Mvele, J.F. Mayoh, V.P. Mbouapougnigni, R. Ngoumé, Valorisation des Fonctions Multiples des Champignons Mycorhiziens Arbusculaires pour la Production Agricole In: Duponnois R., Hafidi M., Ndoye I., Ramanankierana H., Amadou M. B. (eds). Des Champignons Symbiotiques Contre la Désertification des Ecosystèmes Méditerranéens, Tropicaux et Insulaires. Institut de Recherche pour le Développement, Marseille, France, 2013, pp. 156-176.

[4] D. Nwaga, B. Mbarga, E.H. Biye, E.R. Atangana, et M.E.L. Ngonkeu, Diversité des Mycorhizes Arbusculaires et Biomasse Microbienne du Sol de Forêts Denses Humides du Cameroun : Effets des Systèmes d'Utilisation des Terres. Annuaire de la Faculté des Sciences de l’Université de Yaoundé I, Cameroun, vol 2, pp. 18-27, 2003.

[5] D. Nwaga, J. Jansa, A.M. Abossolo, and E. Frossard, "The potential of soil beneficial microorganisms for slash-and-burn agriculture in the humid forest zone of sub-saharan Africa," In: soil biology and agriculture in the tropics, Ed Dion P. Springer Heidelberg Dordrecht. London, New York, 2010, pp. 80-107. https://doi.org/10.1007/978-3642-05076-3_5.

[6] Z.A. Siddiqui, et R. Kataoka, "Mycorrhizal inoculants: progress in inoculant production technology," In: microbes and microbial technology: agricultural and environmental applications, Ahmad et al. (eds.), Springer, New York, 2011, pp. 491-494 https://doi.org/10.1007/978-1-4419-7931-5_18.

[7] J.C. Dodd, C.L. Boddington, A. Rodriguez, C. Gonzalez-Chavez, I. Mansur." Mycelium of arbuscular mycorrhizal fungi (AMF) from different genera: form, function and detection." Plant Soil, vol. 226, pp 131-151, November 2000. https://doi.org/10.1023/A:1026574828169.

[8] S. Timonen, F.A. Smith, S.E. Smith. "Microtubules of mycorrhizal fungus Glomus intraradices in symbiosis with tomato roots." Canadian Journal of Botany, vol. 79, pp. 307-313, March 2001. https://doi.org/10.1139/b01-005.

[9] V. Gadkar, and A. Adholeya, "Intraradical sporulation of AM Gigaspora margarita in long-term axenic cultivation in Ri T-DNA carrot root." Mycological Research, vol. 104, No. 6, pp. 716-721, June 2000. https://doi.org/10.1017/S0953756299002312.

[10] P. Chellappan, S.A.A. Christy, and A. Mahadevan, "Multiplication of arbuscular mycorrhizal fungi on roots," In: Techniques in Mycorrhizal Studies, Mukerji, K.G., Manoharachary, C., Chamola, B.P. (eds.), Kluwer Academic Publishers, The Netherlands, 2001, pp. 285-297. https://doi.org/10.1007/978-94-017-3209-3_15.

[11] D.J. Bagyaraj, "Mycorrhizal association in plants," In: Manual of Mycorrhiza Technology, D.J. Bagyaraj, A Manjunath, (eds.), University of Agriculture Sciences, Bangalore, India, 1992.

[12] [12] K. Tawaraya, "Arbuscular mycorrhizal dependency of different plant species and cultivars," Soil Science and Plant Nutrition, vol. 49, no $5, \quad$ pp. 655-668, November 2003. https://doi.org/10.1080/00380768.2003.10410323.

[13] A. Destinoble, "Effet de la Symbiose Mycorhizienne Arbusculaire sur la Composition Minérale du Poireau Cultivé en Présence de Carbonate de Calcium". Mémoire de Maitrise, Universite Laval, Québec, Canada, 2017.

[14] S.T. Okiobé, M. Abossolo Angue, B.P. Bougnom, Boyomo Onana, D Nwaga, "Improvement of arbuscular mycorrhizal fungi inoculum production by nutrient solution concentration and soil texture variation," International Journal of Agronomy and Agricultural Research, vol 6, no 5, pp. 7-20, April 2015.

[15] P.P. Kormanik, and A.C. Mc graw, "Quantification of vesiculararbuscular Mycorrhizae in plant roots," In: Shenk N.C. (ed). Methods and principles of mycorrhizal research, The American Phytopathological Society, St Paul, MN., 1982, pp. 37-45.

[16] N.C. Schenck, and Y. Perez, "Manual for the identification of VA mycorrhizal fungi"3rd ed., Synergistic Publication, Gaines ville, Florida, USA, 1982, pp. 45-57.

[17] S. Bazot, "Contribution à l'Etude de l'Allocation des Photoassimilats Récents dans la Plante et la Rhizosphère chez une Graminée Pérenne (Lolium perenne L.)," Thèse de Doctorat, Institut National Polytechnique de Lorraine, Lorraine, France, 2005.

[18] Hawaou, "Lutte Contre les Bio-agresseurs pour la Production de l'Oignon (Allium cepa L.) à partir des Microorganismes Bénéfiques : Champignons Mycorhiziens et Agent de Bio Contrôle,” Mémoire de 
Master, Département de Microbiologie, Université de Yaoundé I, Yaoundé, Cameroun, 2018.

[19] M.J Daft, and A.A. Elgiahmi, "Effects of defoliation light on selected hosts" New Phytologist, vol. 80, pp. 365-372, March 1978 https://doi.org/10.1111/j.1469-8137.1978.tb01570.x.

[20] C. Zeng, J.B. Zhang, F. Zhang, and J.D. Bever, "Shading decreases plant carbone preferencial allocation towards the most beneficial mycorrhizal mutualist," New Phytologist, Vol. 205, pp. 361-368, July 2015. https://doi.org/10.1111/nph.13025.

[21] S. Adamou, R. Fokom, M.S. Mandou, V. Mbouapouognigni, A. Ngakou, and D. Nwaga, "Functional diversity of five species of arbuscular mycorhizal fungi in symbiosis with Allium cepa L," IOSR Journal of Agriculture and Veterinary Sciences, vol. 12, no 2, pp. 0108, February 2019.

[22] D. Xiao, Y. Tan, X. Liu, R. Yang, W. Zhang, W., X. He, K. Wang, "Effects of different legume species and densities on arbuscular mycorrhizal fungal communities in a karst grassland ecosystem," Science of the Total Environment, vol. 678, pp. 551-558, May 2019 https://doi.org/10.1016/j.scitotenv.2019.04.293.

[23] K. Saito, Y. Suyama, S. Sato, and K. Sugawara, "Defoliation effects on the community structure of arbuscular mycorrhizal fungi based on $18 \mathrm{~S}$ rDNA sequences," Mycorrhiza, vol. 14, no 6, pp. 363-373, January 2004. https://doi.org/10.1007/s00572-003-0286-x.

[24] A. Pietikainen, and M.-M. Kytoviita, "Defoliation changes mycorrhizal benefit and competitive interactions between seedlings and adult plants," Journal of Ecology, vol. 95, pp. 639-647, May 2007. https://doi.org/10.1111/j.1365-2745.2007.01257.x.

[25] M. IJdo, N. Nicolas Schtickzelle, S. Cranenbrouck, and S. Declerck, "Do arbuscular mycorrhizal fungi with contrasting life-history strategies dijer in their responses to repeated defoliation?" FEMS Microbiology Ecology, vol. 72, pp. 114-122, April 2010 https://doi.org/10.1111/j.1574-6941.2009.00829.x.

[26] A.R. Kula, D. C. Hartnett, and G. W. T. Wilson, "Effects of mycorrhizal symbiosis on tallgrass prairie plant-herbivore interactions" Ecology Letters, vol. 8, no 1, pp. 61-69, December 2004 https://doi.org/10.1111/j.1461-0248.2004.00690.x.

[27] D.B. Bahabege, "Impact de l'Allocation du Carbone sur la Symbiose poireau (Allium porrum L.) -Champignons Mycorhyziens : Densité du Semis et Coupe", Mémoire de Master, Département de Biologie des Organismes Végétaux, Université de Yaoundé I, Yaoundé, Cameroun, 2017.

[28] M.B. McHaffie, and H. Maherali, "Variation in mycorrhizal growth response influences competitive interactions and mechanisms of plant species coexistence," Oecologia, vol. 192, pp. 755-765, January 2020. https://doi.org/10.1007/s00442-020-04609-9. 